\title{
Atopic Dermatitis and Infertility: A Nationwide Retrospective Cohort Study
}

\author{
Amir Horev $^{a, b}$ Guy Shalom ${ }^{c, d}$ Adi Y. Weintraub ${ }^{b}$ e Tamar Freud $^{d}$ \\ Arnon D. Cohen ${ }^{d, f}$ \\ a Pediatric Dermatology Service, Soroka University Medical Center, Beer Sheva, Israel; b Faculty of Health Sciences, \\ Ben-Gurion University of the Negev, Beer Sheva, Israel; ' Clalit Health Services, Tel Aviv, Israel; 'd Siaal Research Center \\ for Family Medicine and Primary Care, Division of Community Health, Faculty of Health Sciences, Ben-Gurion \\ University of the Negev, Beer Sheva, Israel; ${ }^{e}$ Department of Obstetrics and Gynecology, Soroka University Medical \\ Center, Beer Sheva, Israel; ${ }^{f}$ Department of Quality Measurements and Research, Chief Physician's Office, Clalit \\ Health Services, Tel Aviv, Israel
}

\section{Keywords}

Atopic dermatitis · Atopic eczema · Infertility ·

Epidemiological study

\begin{abstract}
Background: Given that common pathophysiological factors play a role in atopic dermatitis (AD) and infertility, we assumed that the 2 conditions might demonstrate an epidemiological association. Large-scale epidemiological data on this topic are lacking. Objectives: The aim of this work was to evaluate the potential association between AD and infertility in a broad community-based population. Methods: A nationwide retrospective cohort study was conducted, analyzing the association between AD and infertility. We compared AD patients diagnosed by a dermatologist between 2002 and 2018 and a matched control group. The study population was subdivided according to age into adults (age $\geq 18$ years) and children (age $<18$ years), and was further subdivided according to AD severity, classified as either mild or moderate-to-severe according to AD-related drug use and healthcare services utilization. Results: The study included 127,150 patients with AD and 127,071 comparison enrollees. $A D$ was associated with a higher prevalence of infertility
\end{abstract}

karger@karger.com www.karger.com/drm

Karger $\stackrel{\text { ' }}{5}$
(C) 2021 The Author(s)

Published by S. Karger AG, Basel

This is an Open Access article licensed under the Creative Commons Attribution-NonCommercial-4.0 International License (CC BY-NC) (http://www.karger.com/Services/OpenAccessLicense), applicable to the online version of the article only. Usage and distribution for commercial purposes requires written permission. than that of the control group (1.4 and $1.1 \%$, respectively). The prevalence of infertility, per 1,000 patient-years, was increased in patients with AD compared to that of the control group (2.17 and 1.7, respectively). Multivariate analysis for infertility demonstrated that AD was a key risk factor for infertility in both males and females with mild AD and moderate-to-severe AD. Conclusion: A significant association between $A D$ and infertility was observed. This association suggests that infertility may be an additional manifestation of AD. Further studies are warranted to evaluate the impact of $A D$ management in the setting of infertility and vice versa.

(C) 2021 The Author(s)

Published by S. Karger AG, Basel

\section{Introduction}

Infertility is defined as the failure to achieve a clinical pregnancy after 12 months or more of unprotected sexual intercourse engaged in on a regular basis. Declining fertility rates are concerning and considered a major public health problem, affecting $10-15 \%$ of couples world-

A.H. and G.S. contributed equally to this work.

Correspondence to:

Amir Horev, amirhor@ clalit.org.il 
wide [1]. Infertility remains unexplained even after a standard medical investigation in $30-40 \%$ of cases [2]. In developed countries, female infertility has been reported to account for close to $40 \%$ of infertile couples. Male infertility has been reported to account for close to $10 \%$. Both male and female infertility have accounted for about $35 \%$, and the remainder remains unknown [3]. Some of the most common causes of infertility include ovulatory disorders, endometriosis, pelvic adhesions, tubal abnormalities, hyperprolactinemia, sperm count, morphology, and function disorders [3]. Atopic dermatitis (AD) is a chronic, common, relapsing inflammatory skin disorder. In large epidemiological studies, the prevalence of $\mathrm{AD}$ was found to be as high as $30 \%$ for children [4] and up to $10 \%$ for adults [5]. In recent years, studies have demonstrated associations between $\mathrm{AD}$ and extracutaneous medical conditions [6], including a comorbidity linkage between atopy and infertility, revealing that atopic women had fewer children than non-atopic women $[7,8]$. The etiologies of these comorbid conditions are complex and most likely multifactorial, involving epidermal structure abnormalities and dysfunction of barrier elements $[9,10]$. Similarly, barrier dysfunctions are closely related to the development of infertility [11], as barrier function is needed for maintaining the immune privilege functions of several sites along the reproductive system.

As common dysfunctions may play a role in these 2 medical conditions, we hypothesized that both disorders might have a common pathophysiological mechanism and demonstrate similar epidemiology. Our study aimed to describe the prevalence of infertility in patients with $\mathrm{AD}$ and investigate the association between $\mathrm{AD}$ and infertility in a real-life setting, using the large medical database of Clalit Health Services (CHS).

\section{Methods}

A nationwide retrospective cohort study was conducted utilizing the CHS computerized database. CHS is the largest public healthcare provider organization in Israel, the second largest worldwide, and serves a population of about 4,600,000 enrollees (representing slightly over half of Israel's total population). The present study was approved by the Institutional Review Board (IRB) of the CHS in accordance with the Declaration of Helsinki and all appropriate amendments.

$\mathrm{AD}$ patients were defined by there being at least one documented diagnosis of $\mathrm{AD}$ registered in the medical records by a dermatologist between the years 2002 and 2018. To increase our study sensitivity and specificity, the codes we used were entered solely by dermatologists. Control patients consisted of a random sample of CHS enrollees' general population, age- and sex-matched, without AD. Other atopic disorders were not exclusion criteria from this group. The study population was subdivided according to age (we used the age of 18 years as an arbitrary cutoff), into adults (age $\geq 18$ years) and children (age $<18$ years). Considering the longitudinal nature of this study, children with $\mathrm{AD}$ were added to the population; that is, given that they could later in life be diagnosed with infertility, their inclusion could contribute to the study results. The study population was further subdivided according to AD severity, with AD being classified as either mild or moderate-to-severe. This subdivision was based on $\mathrm{AD}$-related drug use (topical vs. systemic treatments) and healthcare services utilization that was AD related (i.e., positive medical history of hospitalization for $\mathrm{AD}$ exacerbation). Patients with $\mathrm{AD}$ were considered to have moderate-tosevere AD if they had 1 of the following 3 criteria: 1 , at least one hospitalization due to $\mathrm{AD}$ exacerbation; 2, at least one course of systemic AD-related medications - methotrexate, ciclosporin, azathioprine, or mycophenolate mofetil - prescribed adjacently to a diagnosis of $\mathrm{AD}$ with more than 2 succeeding prescriptions over a period of more than 4 weeks; 3 , phototherapy treatment that was prescribed with the indication of $\mathrm{AD}$. Clinical and demographic characteristics of the study population included age, sex, socioeconomic status, ethnicity, smoking status, body mass index, obesity, systemic eczema-related drug exposure (methotrexate, ciclosporin, azathioprine, or mycophenolate mofetil), and other risk factors for infertility that are relevant for both sexes (diabetes, hypertension, hyperthyroidism, and hypothyroidism).

\section{Outcome Assessment}

Infertility patients were defined by there being at least one documented diagnosis of infertility registered in the medical records between the years 2002 and 2018. Infertility diagnoses were extracted from the CHS chronic diseases registry. The chronic diseases registry is subject to a continuous validation process based on repeated appraisal of diagnoses from several sources. For instance, in this registry, diagnoses such as infertility are validated by the CHS register via a systematic methodology. The validation process is based on a repeated appraisal of diagnoses made by CHS physicians, registered prescriptions, pharmacy claims, laboratory tests (e.g., FSH and LH blood level), and auxiliary tests and treatments (e.g., infertility unit treatments), for each patient. A comparison between these various sources is performed on an ongoing basis, and inconsistencies between the records are resolved, either by authentication by the registry manager or by removing diagnoses from the registry. All the exposure variables/confounders defined in the current study are listed as targets in the CHS chronic disease registry and were extracted from there. Patients with conditions that might affect fertility, such as alcohol abuse, drug abuse, cystic fibrosis, hyperprolactinemia, pituitary adenomas, organ transplantation, cirrhosis, and malignancy, were excluded from the study.

\section{Statistical Analysis}

$\mathrm{AD}$ patients and their age- and gender-matched controls were followed for the incidence of infertility from January 2002 to January 2018. Analyses of risk for infertility were performed in Cox regression models adjusted for age, sex, smoking status, obesity, hypertension, diabetes, hyper- and hypothyroidism, and exposure to eczema-related systemic medications that might affect fertility: methotrexate, azathioprine, mycophenolate mofetil, and ciclosporin. The proportion of patients with a recorded diagnosis of infertility was compared between patients with and without AD by uni- 
Table 1. Baseline characteristics of the study population

\begin{tabular}{|c|c|c|c|c|}
\hline & $\begin{array}{l}\text { General population } \\
(n=127,071)\end{array}$ & $\begin{array}{l}\text { AD (all ages, } \\
\text { both sexes) } \\
(n=127,150)\end{array}$ & $\begin{array}{l}\text { Adult AD } \\
(n=42,548)\end{array}$ & $\begin{array}{l}\text { Adult moderate- } \\
\text { to-severe AD } \\
(n=3,022)\end{array}$ \\
\hline Mean age, years (SD) & $14.9(18.9)$ & $14.9(18.9)$ & $41.1(18.3)$ & $49.7(19.9)$ \\
\hline \multicolumn{5}{|l|}{ Sex } \\
\hline Women & $66,911(52.7)$ & $67,028(52.7)$ & $26,782(62.9)$ & $1,706(56.5)$ \\
\hline Men & $60,160(47.3)$ & $60,122(47.3)$ & $15,766(37.1)$ & $1,316(43.5)$ \\
\hline \multicolumn{5}{|l|}{ Socioeconomic status ${ }^{\mathrm{a}}$} \\
\hline Low & $45,601(36.3)$ & $45,547(36.2)$ & $13,398(31.6)$ & $942(31.3)$ \\
\hline Medium & $50,710(40.4)$ & $50,935(40.5)$ & $18,110(42.8)$ & $1,286(42.7)$ \\
\hline High & $29,225(23.3)$ & $29,252(23.3)$ & $10,843(25.6)$ & $786(26.1)$ \\
\hline \multicolumn{5}{|l|}{ Ethnicity } \\
\hline Arabs & $23,125(18.2)$ & $23,165(18.2)$ & $3,774(8.9)$ & $237(7.8)$ \\
\hline Non-Arabs & $103,899(81.8)$ & $103,940(81.8)$ & $38,774(91.1)$ & $2,785(92.2)$ \\
\hline Smoking & $16,441(12.9)$ & $15,571(12.2)$ & $14,619(34.4)$ & $1,177(38.9)$ \\
\hline Severe AD & - & $4,346(2.3)$ & $3,022(7.1)$ & $3,022(100)$ \\
\hline Mean BMI (SD) & $23.9(46.45)$ & $24.0(59.3)$ & $25.9(5.2)$ & $26.5(5.6)^{\mathrm{a}}$ \\
\hline Obesity & $17,552(13.8)$ & $18,549(14.5)$ & $7,648(18)$ & $735(24.3)^{\mathrm{a}}$ \\
\hline Diabetes & $4,111(3.2)$ & $4,134(3.3)$ & $5,125(12)$ & $644(21.3)^{\mathrm{a}}$ \\
\hline Hypertension & $6,657(5.2)$ & $6,648(5.2)$ & $8,802(20.7)$ & $1,090(36.1)^{\mathrm{a}}$ \\
\hline Hyperthyroidism & $437(0.3)$ & $522(0.4)$ & $552(1.3)$ & $50(1.7)^{\mathrm{a}}$ \\
\hline Hypothyroidism & $3,166(2.5)$ & $3,638(2.9)$ & $3,924(9.2)$ & $381(12.6)^{\mathrm{a}}$ \\
\hline Methotrexate exposure & $376(0.3)$ & $666(0.5)$ & $730(1.7)$ & $730(24.2)^{\mathrm{a}}$ \\
\hline Azathioprine exposure & $196(0.2)$ & $323(0.3)$ & $309(0.7)$ & $309(10.2)^{\mathrm{a}}$ \\
\hline Mycophenolate mofetil exposure & $15(0)$ & $23(0)$ & $64(0.2)$ & $64(2.1)^{\mathrm{a}}$ \\
\hline
\end{tabular}

Data are presented as $n(\%)$ or as indicated. Statistically significant values are presented in bold, comparison vs. age- and gender-matched control (2-tailed).

a Values are higher vs. age and gender-matched control.

variate analyses using the $\chi^{2}$ test. Continuous variables were compared using $t$ tests. Statistical analysis was performed using the SPSS version 23 software (SPSS Inc., Chicago, IL, USA). A $p$ value $<0.05$ was considered statistically significant.

\section{Results}

During the study period, 127,150 patients fulfilled the inclusion criteria and comprised the AD group. The comparison group comprised 127,071 age- and sex-matched controls. Among AD patients, 42,548 (33.5\%) were adults, and of these, 3,022 patients (7.1\%) had moderate-to-severe AD. Patients with moderate-to-severe AD had a statistically significantly higher prevalence of obesity, diabetes mellitus, hypertension, hyperthyroidism, hypothyroidism, and had significantly higher exposure to systemic immunosuppressive medications such as methotrexate, azathioprine, and mycophenolate mofetil. The demographic and clinical characteristics of the study population are presented in Table 1.
Table 2 presents the association between infertility and $\mathrm{AD}$ in the entire study population (all ages, both sexes). The prevalence of infertility in patients with $\mathrm{AD}$ was higher compared to the prevalence of infertility in the control group (1.4 and 1.1\%, respectively). The prevalence of infertility per 1,000 patient-years was higher among patients with $\mathrm{AD}$ compared to that of the control group (2.17 and 1.7, respectively). The association between infertility and AD remained statistically significant in most subgroups.

Multivariate Cox regressions analysis for infertility in adults with $\mathrm{AD}$ (mild and moderate-to-severe) and adults with moderate-to-severe $\mathrm{AD}$ by gender are presented in Tables 3 and 4 . In adults with AD, statistically significant risk factors for infertility in the entire group were $\mathrm{AD}$ (HR $1.11,95 \%$ CI 1.01-1.21), age (HR 1.03, 95\% CI 1.02-1.04), smoking (HR 1.19, 95\% CI 1.08-1.31), hypothyroidism (HR 1.56, 95\% CI 1.35-1.8), methotrexate exposure (HR 2.63, 95\% CI 1.5-4.6), mycophenolate mofetil exposure (HR 2.81, 95\% CI 1.22-6.49), and ciclosporin exposure (HR 2.59, 95\% CI 1.38-4.87). When comparing males 
Table 2. Number of events: primary infertility and infertility-related conditions - general population enrollees versus the entire group of patients with $\mathrm{AD}$

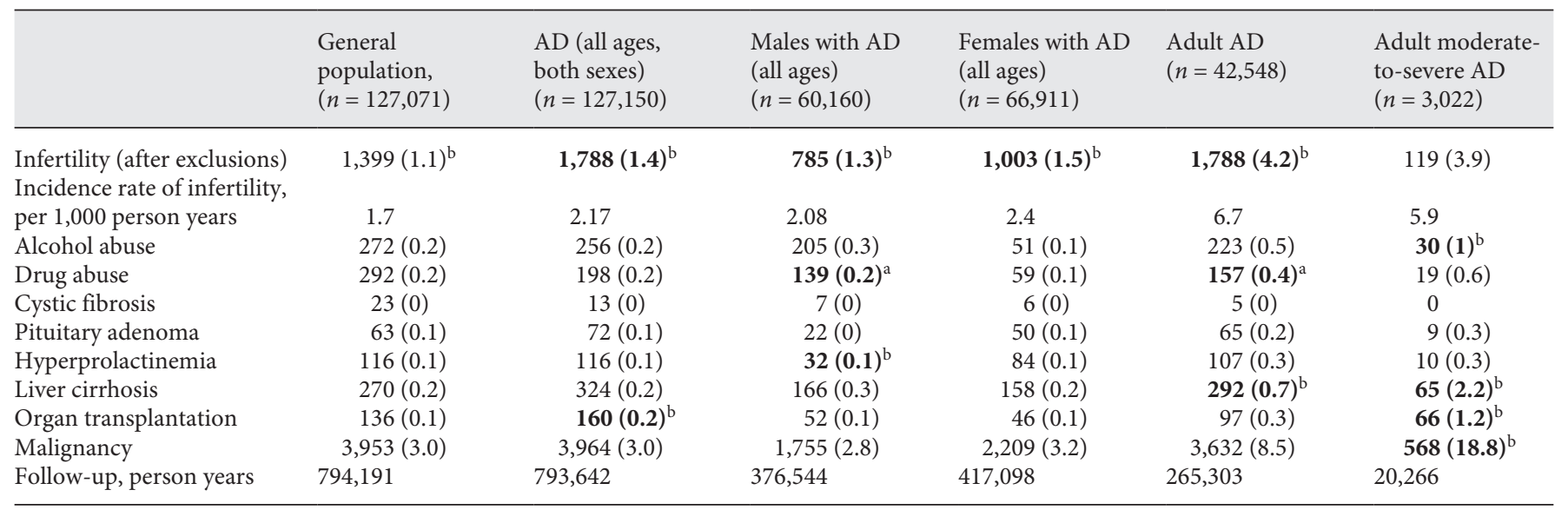

Data are presented as $n(\%)$ or as indicated. Statistically significant values are presented in bold, comparison vs. age and gender-matched controls. AD, atopic dermatitis; CI, confidence interval.

a Values are lower vs. age, and gender-matched controls.

${ }^{\mathrm{b}}$ Values are higher vs. age, and gender-matched controls.

Table 3. Cox regression results for the association between investigated risk factors and hazard ratios for infertility by gender (adults with $\mathrm{AD}$ vs. controls)

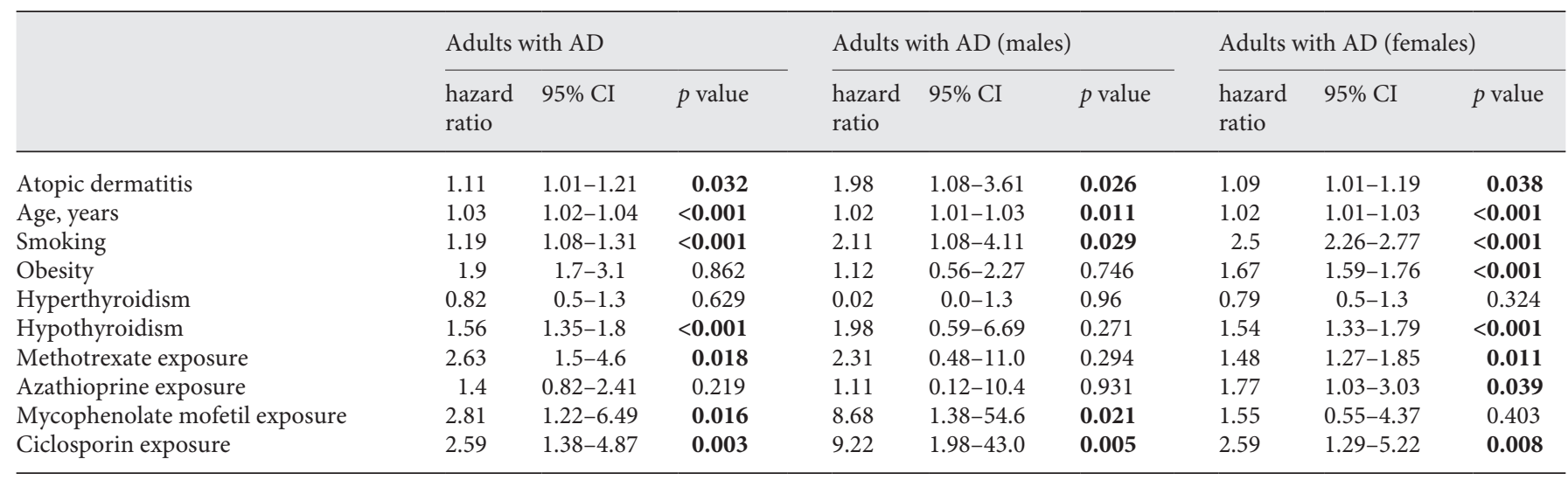

Hazard ratios are adjusted for age, sex, smoking status, obesity, hypertension, diabetes, hyper- and hypothyroidism, and exposure to methotrexate, azathioprine, mycophenolate mofetil, and ciclosporin. Statistically significant values are presented in bold.

and females in this group, the main difference was that females' significant risk factors for infertility included hypothyroidism, obesity, and azathioprine exposure, and lacked mycophenolate mofetil exposure (Table 3). Among the adults in the moderate-to-severe AD subgroup, statistically significant risk factors for infertility were similar to those of the adults with $\mathrm{AD}$ group, excluding hypothyroidism and exposure to mycophenolate mofetil and ciclosporin. The main difference between male and female risk factors for infertility in this group was that male risk factors included hypothyroidism and exposure to mycophenolate mofetil and ciclosporin and lacked methotrexate exposure (Table 4).

\section{Discussion}

We investigated the association between $\mathrm{AD}$ and infertility in an extensive, community-based healthcare database. In univariate analyses, $\mathrm{AD}$ in the general popula- 
Table 4. Cox regression results for the association between investigated risk factors and hazard ratios for infertility by gender (adults with moderate-severe $\mathrm{AD}$ vs. controls)

\begin{tabular}{|c|c|c|c|c|c|c|c|c|c|}
\hline & \multicolumn{3}{|c|}{$\begin{array}{l}\text { Adults with moderate-to-severe } \\
\mathrm{AD}\end{array}$} & \multicolumn{3}{|c|}{$\begin{array}{l}\text { Adults with moderate-to-severe AD } \\
\text { (males) }\end{array}$} & \multicolumn{3}{|c|}{$\begin{array}{l}\text { Adults with moderate-to-severe } \\
\mathrm{AD} \text { (females) }\end{array}$} \\
\hline & $\begin{array}{l}\text { hazard } \\
\text { ratio }\end{array}$ & $95 \%$ CI & $p$ value & hazar & $95 \%$ CI & $p$ value & $\begin{array}{l}\text { hazard } \\
\text { ratio }\end{array}$ & $95 \% \mathrm{CI}$ & $p$ value \\
\hline Atopic dermatitis & 1.26 & $1.07-2.02$ & 0.035 & 1.59 & $1.2-2.1$ & 0.001 & 1.26 & $1.07-2.02$ & 0.034 \\
\hline Age, years & 1.04 & $1.01-1.05$ & $<0.001$ & 1.02 & $1.01-1.03$ & $<0.001$ & 1.02 & $1.01-1.04$ & $<0.001$ \\
\hline Smoking & 1.65 & $1.06-2.56$ & 0.027 & 1.28 & $1.1-1.5$ & $<0.001$ & 1.65 & $1.06-2.5$ & 0.027 \\
\hline Hypothyroidism & 1.28 & $0.67-2.44$ & 0.458 & 1.54 & $1.2-1.9$ & $<0.001$ & 1.27 & $0.67-2.4$ & 0.458 \\
\hline Methotrexate exposure & 1.55 & $1.32-1.97$ & 0.038 & 1.67 & $0.4-2.9$ & 0.158 & 1.55 & $1.32-1.97$ & 0.038 \\
\hline Azathioprine exposure & 1.97 & $0.84-4.72$ & 0.121 & 1.15 & $0.7-2.1$ & 0.618 & 1.23 & $0.72-2.13$ & 0.451 \\
\hline Mycophenolate mofetil exposure & 1.23 & $0.72-2.13$ & 0.451 & 2.5 & $1.1-5.7$ & 0.037 & 1.97 & $0.84-4.62$ & 0.121 \\
\hline Ciclosporin exposure & 1.78 & $0.95-3.33$ & 0.07 & 1.78 & $1.05-3.33$ & 0.007 & 1.78 & $0.96-3.33$ & 0.07 \\
\hline
\end{tabular}

Hazard ratios are adjusted for age, smoking status, obesity, hypertension, diabetes, hyper- and hypothyroidism, and exposure to methotrexate, azathioprine, mycophenolate mofetil, and ciclosporin. Statistically significant values are presented in bold.

tion was associated with a higher prevalence of infertility. These observations remained significant after controlling for conditions related to infertility. Multivariate analysis for infertility demonstrated a significant increase in infertility rates in both males and females with AD. Not surprisingly, an increase in infertility rates was observed in patients in the moderate-to-severe AD subgroup as well.

Comorbidity linkage between atopy and infertility has been suggested in earlier studies, but the available evidence, to date, is sparse and conflicting. Blafoss et al. [12] summarized the impact of female asthma and atopy on fertility in their systematic review. Only 6 studies investigating the association between female atopy and the number of offspring were found. Two studies reported a decrease in the number of offspring in atopic women compared to non-atopic women $[8,9]$. In contrast, 2 studies found no difference $[13,14]$, and 2 additional studies found an actual increase in the number of offspring in atopic women $[15,16]$. Overall, Blafoss et al. [12] concluded that there was a clear trend toward an association between female atopy and a reduction of fertility; hence, higher rates of atopic women require fertility treatments. One of the main pathophysiological theories regarding $\mathrm{AD}$ involves dysfunction of the natural skin barrier [10]. Claudins are essential adhesive membrane proteins that are found in different organs. Abnormal claudin-1 function in $\mathrm{AD}$ will result in dysfunction of the tight junction and, in turn, the stratum corneum barrier. In addition, studies have shown through Western blot analysis that skin from patients with $\mathrm{AD}$ has lower amounts of claudin-1 than does normal skin [17]. Claudins are essential components of cellular tight junctions and adherens junctions in the endometrium as well. Claudins are thought to play a role in different phases of the menstrual cycle [18]. Abnormal claudins function and expression have been associated with several pathological processes in the uterus, such as infertility [19], endometrial carcinoma [20], and endometriosis [21]. These findings suggest a correlation between $\mathrm{AD}$, the menstrual cycle, and uterine abnormalities. In males, the blood-testis barrier is a physical barrier between blood vessels and the seminiferous tubules in the testicles. The barrier functions as an impermeable "seal," separating and protecting the adluminal germ cells from general circulation, which is crucial for germ cell maturation and maintenance. Also, the blood-testis barrier provides an immune-tolerant microenvironment for spermatozoa. This immune privilege state of the testis is vital, and dysfunction may result in immunologic infertility [11]. Sertoli cell tight junctions play an essential role in spermatogenesis as the major component of the blood-testis barrier of the seminiferous epithelium, and claudins are a critical transmembrane protein component of this epithelium [22]. Occludin is another transmembrane protein common to the blood-testis barrier [22] and the skin barrier [23]. Occludins, like claudins, are essential for the healthy barrier structure and function, and abnormalities in their function, quantity, or expression are noted in patients with $\mathrm{AD}$ [24] and in those with spermatogenesis dysfunction [25]. These links of common protein defects 
in male and female reproductive pathways and the skin of $\mathrm{AD}$ patients are in accordance with the association seen in our study between AD and infertility in both sexes. Given that $\mathrm{AD}$ is an inflammatory disorder [6], and as other inflammatory disorders such as rheumatoid arthritis [26] and asthma [14] have been associated with infertility, it is reasonable to hypothesize that systemic inflammation related to AD may account for, at least in part, some cases of infertility. Inflammation can affect male and female infertility in various mechanisms. In males, both chronic inflammation and immunomodulatory drugs/immunosuppressants may impact the semen quality by altering accessory gland functions, impeding sperm transport, or directly dysregulating spermatogenesis [27]. Possible mechanisms in females could be, among others, inflammatory changes in the uterus and infiltration of inflammatory cells into the endometrial lining, as well as lower levels of vascular endothelial growth factor [12].

This study was a real-life, large, registry-based retrospective study focusing on patients diagnosed with $\mathrm{AD}$ by dermatologists in primary care and community settings. Nevertheless, it holds inherent limitations to this type of study design. One such limitation is the possibility of missing data. The database is limited in its knowledge of the patient's partnership status or willingness to conceive. However, due to cultural and religious circumstances, both the Jewish and the Muslim society in Israel have a high desire to conceive and high birth rates that are increasing over time. In 2016, 181,405 babies were born, an increase of $92 \%$ from 1980 [28]. The total fertility rate was 3.11, higher than the rate in all OECD member countries. While we cannot soundly distinguish between patients with a fertility problem to those with low willingness to conceive, we believe that it is safe to assume that the desire for conception in our population is generally strong and increasing. Naturally, exploring large datasets may amplify slight differences that can be detected even when they are of limited relevance in clinical practice. Our study demonstrated a subtle yet significant higher risk of infertility in the $\mathrm{AD}$ population; however, this observation has imperative and meaningful clinical applications from a public health perspective. The definitive severity assessment measure of $\mathrm{AD}$ is the "Severity Scoring of Atopic Dermatitis" (SCORAD) index [29]. According to our study's retrospective nature, the information required to assess disease severity according to the SCORAD could not be drawn from the $\mathrm{CHS}$ database. We tried to bypass this limitation by evaluating disease severity by proxy, based on healthcare ser- vices utilization and prescribed treatments. This method has been found to have a high positive predictive value and has been used successfully in previous publications $[30,31]$. Lastly, information regarding improvement in symptoms or recovery of patients with $\mathrm{AD}$ and the possible effect on infertility could not be drawn, and further prospective studies are warranted to address this issue. Despite these limitations, this study reveals important data about patients with $\mathrm{AD}$ and supports efforts to improve $\mathrm{AD}$ care quality.

In conclusion, our study adds epidemiological evidence regarding an association between $\mathrm{AD}$ and infertility. This significant association suggests that infertility may be an additional manifestation of AD. Further studies are warranted to evaluate the impact of $\mathrm{AD}$ management in the setting of infertility and vice versa.

\section{Key Message}

This study adds essential epidemiological evidence of an association between atopic dermatitis and infertility.

\section{Statement of Ethics}

The present study was conducted in accordance with the Declaration of Helsinki and all appropriate amendments. The study was approved by the Ethics Review Committee of Clalit Health Services, Israel.

\section{Conflict of Interest Statement}

A.H., G.S., A.Y.W., and T.F. have no conflicts of interest to declare. A.D.C. served as a consultant, advisor, or speaker to AbbVie, Amgen, Boehringer Ingelheim, Dexcel pharma, Janssen, Kamedis, Lilly, Neopharm, Novartis, Perrigo, Pfizer, Rafa, Sanofi, Sirbal, and Taro.

\section{Funding Sources}

This work was funded by an unrestricted grant from Pfizer Inc.

\section{Author Contributions}

All authors contributed to the study conception and design. Material preparation, data collection and analysis were performed by Guy Shalom, Tamar Freuid, and Arnon Cohen. The first draft of the manuscript was written by Amir Horev and all authors commented on previous versions of the manuscript. All authors read and approved the final version of the manuscript. 


\section{References}

1 Arslan M, Bocca S, Mirkin S, Barroso G, Stadtmauer L, Oehninger S. Controlled ovarian hyperstimulation protocols for in vitro fertilization: two decades of experience after the birth of Elizabeth Carr. Fertil Steril. 2005 Sep;84(3):555-69.

2 Recent advances in medically assisted conception. Report of a WHO Scientific Group. World Health Organ Tech Rep Ser. 1992;820: $1-111$.

3 Gelbaya TA, Potdar N, Jeve YB, Nardo LG. Definition and epidemiology of unexplained infertility. Obstet Gynecol Surv. 2014 Feb; 69(2):109-15.

4 Odhiambo JA, Williams HC, Clayton TO, Robertson CF, Asher MI; ISAAC Phase Three Study Group. Global variations in prevalence of eczema symptoms in children from ISAAC Phase Three. J Allergy Clin Immunol. 2009 Dec;124(6):1251-8.e23.

5 Silverberg JI, Hanifin JM. Adult eczema prevalence and associations with asthma and other health and demographic factors: a US population-based study. J Allergy Clin Immunol. 2013 Nov; 132(5):1132-8.

6 Brunner PM, Silverberg JI, Guttman-Yassky E, Paller AS, Kabashima K, Amagai M, et al.; Councilors of the International Eczema Council. Increasing comorbidities suggest that atopic dermatitis is a systemic disorder. J Invest Dermatol. 2017 Jan;137(1):18-25.

7 Sunyer J, Antó JM, Harris J, Torrent M, Vall O, Cullinan P, et al.; AMICS study. Asthma Multi-centre Infants Cohort Study. Maternal atopy and parity. Clin Exp Allergy. 2001 Sep; 31(9):1352-5

8 Karmaus W, Eneli I. Maternal atopy and the number of offspring: is there an association? Pediatr Allergy Immunol. 2003 Dec;14(6): 470-4.

9 Silverberg JI. Associations between atopic dermatitis and other disorders. F1000 Res. 2018 Mar;7:303.

10 Kim J, Kim BE, Leung DY. Pathophysiology of atopic dermatitis: clinical implications. Allergy Asthma Proc. 2019 Mar;40(2):84-92.

11 Archana SS, Selvaraju S, Binsila BK, Arangasamy $A$, Krawetz SA. Immune regulatory molecules as modifiers of semen and fertility: A review. Mol Reprod Dev. 2019 Nov;86(11): 1485-504.
12 Bláfoss J, Hansen AV, Malchau Lauesgaard SS, Ali Z, Ulrik CS. Female asthma and atopy - impact on fertility: a systematic review. J Asthma Allergy. 2019 Jul;12(12):205-11.

13 Sunyer J, Antó JM, Plana E, Janson C, Jarvis D, Kony S, et al.; European Community Respiratory Health Study. Maternal atopy and changes in parity. Clin Exp Allergy. 2005 Aug; 35(8):1028-32.

14 Gade EJ, Thomsen SF, Lindenberg S, Kyvik KO, Lieberoth S, Backer V. Asthma affects time to pregnancy and fertility: a registerbased twin study. Eur Respir J. 2014 Apr; 43(4):1077-85.

15 Nilsson L, Kjellman NI, Löfman O, Björkstén B. Parity among atopic and non-atopic mothers. Pediatr Allergy Immunol. 1997 Aug;8(3): 134-6.

16 Tata LJ, Hubbard RB, McKeever TM, Smith CJ, Doyle P, Smeeth L, et al. Fertility rates in women with asthma, eczema, and hay fever: a general population-based cohort study. Am J Epidemiol. 2007 May;165(9):1023-30.

17 Yuki T, Tobiishi M, Kusaka-Kikushima A, Ota Y, Tokura Y. Impaired tight junctions in atopic dermatitis skin and in a skin-equivalent model treated with interleukin-17. PLoS One. 2016 Sep;11(9):e0161759.

18 Sobel G, Németh J, Kiss A, Lotz G, Szabó I, Udvarhelyi N, et al. Claudin 1 differentiates endometrioid and serous papillary endometrial adenocarcinoma. Gynecol Oncol. 2006 Nov;103(2):591-8.

19 Mikołajczyk M, Wirstlein P, Skrzypczak J. Aberrant claudin-4 transcript levels in eutopic endometrium of women with idiopathic infertility and minimal endometriosis. Ginekol Pol. 2013 Feb;84(2):90-4.

20 Agarwal R, D'Souza T, Morin PJ. Claudin-3 and claudin-4 expression in ovarian epithelial cells enhances invasion and is associated with increased matrix metalloproteinase- 2 activity. Cancer Res. 2005 Aug;65(16):7378-85.

21 Gaetje R, Holtrich U, Engels K, Kissler S, Rody A, Karn T, et al. Differential expression of claudins in human endometrium and endometriosis. Gynecol Endocrinol. 2008 Aug; 24(8):442-9.
22 McCabe MJ, Foo CF, Dinger ME, Smooker PM, Stanton PG. Claudin-11 and occludin are major contributors to Sertoli cell tight junction function, in vitro. Asian J Androl. 2016 Jul-Aug;18(4):620-6.

23 Sugawara T, Iwamoto N, Akashi M, Kojima T, Hisatsune J, Sugai M, et al. Tight junction dysfunction in the stratum granulosum leads to aberrant stratum corneum barrier function in claudin-1-deficient mice. J Dermatol Sci. 2013 Apr;70(1):12-8.

24 David Boothe W, Tarbox JA, Tarbox MB. Atopic dermatitis: pathophysiology. Adv Exp Med Biol. 2017;1027:21-37.

25 Yang XF, Fu C, Liu YQ, Liu RS, Feng H, Huang RY, et al. [Expression of CLAUDIN-11 in the testicular tissue of the patient with non-obstructive azoospermia and its clinical significance]. Zhonghua Nan Ke Xue. 2018 Mar;24(3):221-5.

26 Provost M, Eaton JL, Clowse ME. Fertility and infertility in rheumatoid arthritis. Curr Opin Rheumatol. 2014 May;26(3):308-14.

27 Finelli R, Leisegang K, Finocchi F, De Masi S, Agarwal A, Damiani G. The impact of autoimmune systemic inflammation and associated medications on male reproductive health in patients with chronic rheumatological, dermatological, and gastroenterological diseases: A systematic review. Am J Reprod Immunol. 2021, Online ahead of print.

28 CBS. Births and Fertility in Israel. 2016, Israeli Central Bureau of Statistics. March 13, 2018. https://www.cbs.gov.il/en/mediarelease/ Pages/2018/Births-And-Fertility-In-Israel2016.aspx.

29 Schmitt J, Spuls PI, Thomas KS, Simpson E, Furue M, Deckert S, et al.; HOME initiative collaborators. The Harmonising Outcome Measures for Eczema (HOME) statement to assess clinical signs of atopic eczema in trials. J Allergy Clin Immunol. 2014 Oct;134(4): 800-7.

30 Shalom G, Dreiher J, Kridin K, Horev A, Khoury R, Battat E, et al. Atopic dermatitis and the metabolic syndrome: a cross-sectional study of 116816 patients. J Eur Acad Dermatol Venereol. 2019 Sep;33(9):1762-7.

31 Shalom G, Magen E, Dreiher J, Freud T, Bogen $\mathrm{B}$, Comaneshter $\mathrm{D}$, et al. Chronic urticaria and atopic disorders: a cross-sectional study of 11271 patients. Br J Dermatol. 2017 Oct;177(4):e96-7. 